\title{
Kesyubhatan TIK: Sisi Gelap dan Terang Penggunaan TIK Pada Literasi Digital Pondok Pesantren
}

\author{
Faiz In'amurrohman*1 \\ Universitas Islam Indonesia, Indonesia
}

\section{INFO ARTIKEL}

\begin{abstract}
Alamat Web Artikel:
Journal.umy.ac.id/index.php/
\end{abstract} $\mathrm{mt} /$ article/view/6237

DOI:

https://doi.org/10.18196/mt.010105

Data Artikel:

Diterima:

19 Okt 2019

Direview:

21 Okt 2019

Direvisi:

24 Okt 2019

Disetujui:

31 Okt 2019

Korespondensi:

15917108@students.uii.ac id

\begin{abstract}
ABSTRAK
Media sosial saat ini telah dipenuhi konten-konten yang belum sepenuhnya dapat dipertanggungjawabkan kebenaran dan kredibilitasnya. Dampak buruk yang ditimbulkan mengarah pada pemikiran santri yang tidak arif akibat meluasnya dakwah kaum Islam Radikal yang menyudutkan ajaran pesantren dengan mengabaikan konteks zaman dan kearifan lokal masyarakat. Doktrin kaum Islam Liberal yang menyangkut kebebasan HAM dalam syariat Islam baik ushuliyyah maupun furu'iyyah juga gencar mendekadensi akidah dan moral santri. Selain itu, turut muncul propaganda Barat yang secara masif mendiskreditkan kaum pesantren dengan konstruksi terorisme. Kiai dan santri diharapkan dapat berkontribusi dalam pembelaan siber terhadap ajaran Islam yang rahmatan lil 'alamin yang menjaga kearifan lokal masyarakat melalui kegiatan literasi digital. Literasi digital dapat memberikan banyak pengaruh positif kepada masyarakat dalam berbagai bidang. Namun, dibutuhkan implementasi yang tepat agar fungsi tersebut tidak disalahgunakan dan menggiring massa pada ideologi yang keliru. Langkah yang dapat diambil yaitu mengakuisisi kearifan pengetahuan kiai dan santri yang selanjutnya dipublikasikan secara berkala melalui media sosial guna meneguhkan spiritual dan meluruskan ideologi yang keliru di masyarakat. Melalui penelitian ini didefinisikan dampak dan kemampuan penggunaan TIK pada literasi digital di pesantren yang didukung dengan Individual Competence Framework. Diperoleh dampak positif dan negatif yang dipetakan ke dalam tiga aspek yaitu dakwah, pendidikan, dan sosial. Dampak positif dominan pada aspek pendidikan yaitu memperluas wawasan dan dampak negatif dominan pada aspek sosial yaitu kecanduan penggunaan TIK. Selain itu, kemampuan literasi dipetakan ke dalam tiga tingkat yaitu dasar, menengah, dan mahir berdasarkan dimensi kemampuan teknis, pemahaman kritis, dan kemampuan komunikatif. Diperoleh baik ustadz, pengurus, maupun santri dari 32 pesantren berada pada tingkat menengah. Pada dimensi kemampuan teknis tertinggi dimiliki ustadz dengan level 105.38, pemahaman kritis tertinggi dimiliki santri dengan level 104.09, dan kemampuan komunikatif tertinggi dimiliki pengurus dengan level 105.26
\end{abstract}

Kata Kunci: Dampak TIK, Literasi Digital, Individual Competence Framework

\section{PENDAHULUAN}

Pondok pesantren menyumbang kontribusi besar bagi masyarakat dalam pendidikan karakter dan khazanah keagamaan. Pesantren menjadi satu-satunya institusi budaya yang masih menjaga ajaran para pendahulunya (salaf as-shaleh). Sekalipun kiprahnya sebagai dinamisator pembangun karakter masyarakat, pesantren tidak hanya sebagai institusi pendidikan, melainkan juga institusi perjuangan, sosial, ekonomi, keagamaan, budaya, dan dakwah [1]. Sebagian besar pesantren di Indonesia menggunakan basis salafiyah — mengacu pada sistem pendidikan Islam secara an sich [2]. Pembelajaran yang digunakan masih mempertahankan model kuno dengan sistem bandongan [3]. Kegiatan tersebut bertujuan untuk mengkaji kitab-kitab ulama abad pertengahan yang disajikan dalam teks berbahasa arab dengan pemaknaan menggunakan pegon. Selain materi keagamaan, pesantren mengajarkan juga riyadhah untuk mendukung keilmuan batin.

Kemajuan TIK di tengah masyarakat digital dan masyarakat informasi mulai menggeser peran pesantren. Terlebih tidak sedikit konten-konten keislaman di media sosial yang belum sepenuhnya 
dapat dipertanggungjawabkan kebenaran dan sanad keilmuannya. Dampak buruk yang ditimbulkan dapat mengarah pada pola pikir santri yang cenderung berfikir negatif dan tidak arif [4]. Santri dikhawatirkan terlampau berani meleburkan diri pada budaya modernitas yang berujung pada sikap relativistik-nihilistik untuk menjadi bagian kaum Liberalis [5]. Masih ada dampak lain yang lebih krusial yaitu meluasnya dakwah oleh kaum Islam Radikal dengan menyudutkan ajaran Ahlussunnah wa al-Jama'ah yang dibawa kaum "bersarung" (pesantren). Orang awam didoktrin dengan purifikasi akidah yang mengacu tegas pada zaman Nabi tanpa mempertimbangkan konteks zaman sekarang dan kearifan lokal masyarakat [6]. Seharusnya, Islam adalah ajaran yang rahmatan lil 'alamin yang disampaikan dalam ideologi shaheh fi kulli zamanin wa makanin (benar pada setiap waktu dan tempat) [7]. Di samping itu, doktrinisasi kaum Islam Liberal yang menyangkut kebebasan HAM dalam syariat Islam baik yang bersifat ushuliyyah maupun furu'iyyah juga menjadi penyumbang lain penyerangan akidah [8][9]. Lain dari itu, hadir juga propaganda Barat yang mendiskreditkan kelompok Islam dengan konstruksi terorisme dan kekerasan secara masif dan komprehensif [10]. Padahal, Islam bukanlah agama yang hanya menyeru pada urusan akhirat, melainkan keduniaan pun turut diperhatikan. Oleh karena itu, eksistensi kaum "bersarung" dianggap mampu arif menyikapi permasalahan yang timbul.

Kiai dan santri dapat berkontribusi dalam pembelaan siber terhadap ajaran Islam yang selaras dengan nilai-nilai pesantren dan kearifan lokal masyarakat. Peran yang dapat diambil adalah menggalakkan literasi digital yang bernada amar ma'ruf nahi munkar bi al-rahmah wa al-harishi (menyeru pada kebaikan dan meninggalkan keburukan dengan kasih sayang dan kelembutan hati). Literasi digital dapat memberikan pengaruh positif dalam keberhasilan pembelajaran, meningkatkan kualitas pembelajaran, meningkatkan kinerja, dan ketercapaian usaha, yang dalam hal ini dakwah [11][12][13]. Akan tetapi, perlu diperhatikan bahwa implementasi literasi digital dapat menggiring massa pada ideologi yang keliru. Diperlukan arahan yang tepat agar fungsi tersebut tidak disalahgunakan untuk hal lain yang bertujuan mendiskreditkan ajaran Islam. Langkah memulainya dapat dengan mengakuisisi kearifan pengetahuan kiai-kiai lokal serta santri pesantren yang selanjutnya dipublikasikan secara berkala melalui media sosial guna meluruskan ideologi yang keliru di masyarakat. Langkah tersebut juga dilakukan untuk menjangkau dakwah Islam yang lebih luas.

Namun, 15.057 (52\%) pesantren salaf (tradisional) dari 28.961 di Indonesia [14], sebagian besar masih menarik diri mengikuti dakwah dan pembelajaran berbasis TIK. Hal tersebut dikarenakan budaya salaf yang masih kuat dipegang di pesantren. Berbeda dengan pesantren khalaf (modern) yang telah mengadopsi TIK sebagai sarana pembelajaran klasikal, sehingga santri terbiasa dengan teknologi. Kedua fenomena budaya tersebut menunjukkan disparitas penggunaan TIK di pesantren yang menimbulkan kesenjangan sosial maupun digital. Melalui penelitian ini didefinisikan dampak dan tingkat kemampuan penggunaan TIK pada literasi digital di pesantren salaf yang didukung dengan Individual Competence Framework (ICF).

\section{METODE PENELITIAN}

Jenis penelitian yang digunakan yaitu kualitatif dengan metode pendekatan survei. Survei dilakukan pada 32 pesantren salaf yang tersebar di daerah Banten (1 pesantren), Jawa Barat (3 pesantren), Jawa Tengah (15 pesantren), Yogyakarta (7 pesantren), dan Jawa Timur (6 pesantren). Responden yang terlibat dalam penelitian sebanyak 118 orang yang terdiri dari ustadz, pengurus, dan santri. Pengumpulan data dilakukan dengan metode observasi, wawancara, angket, dan dokumentasi.

Terdapat dua proses utama dalam penelitian ini. Pertama, analisis dampak literasi media bagi $u s t a d z$, pengurus, dan santri di pesantren salaf dengan mendefinisikan sisi terang (dampak positif) dan sisi gelap (dampak negatif). Selanjutnya, dampak-dampak tersebut dipetakan ke dalam tiga aspek yaitu dakwah, pendidikan, dan sosial. Kedua, pengukuran kemampuan ustadz, pengurus, dan santri dalam menggunakan TIK untuk literasi digital. Pengukuran menggunakan indikator ICF yang disesuaikan dengan instrumen penelitian. Hasil dari pengukuran berupa tingkat kemampuan penggunaan media digital yang meliputi dasar, menengah, dan mahir berdasarkan dimensi kemampuan teknis, pemahaman kritis, dan kemampuan komunikatif. Selain itu, pada tahap kedua 
disajikan juga peta sebaran penggunaan TIK guna mengetahui kondisi yang ada di pesantren salaf saat ini. Gambar 1 menunjukkan kerangka konseptual penelitian yang dilakukan.

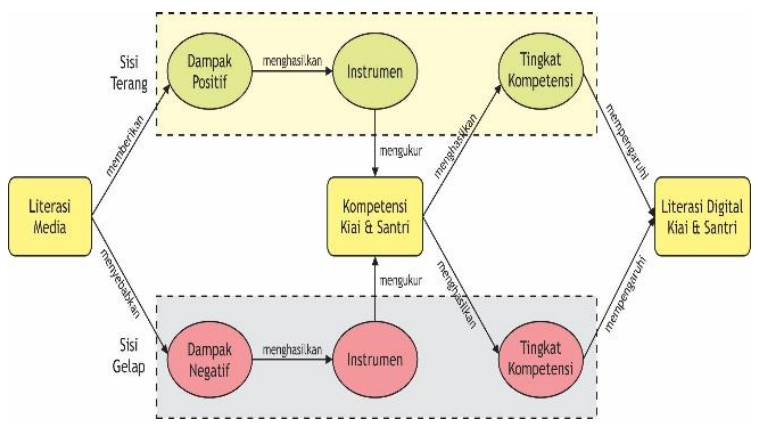

Gambar 1 Kerangka Konseptual

\section{HASIL DAN PEMBAHASAN}

\subsection{Dampak Literasi Media}

Temuan dampak yang diperoleh melalui kajian pustaka dijadikan acuan awal yang selanjutnya divalidasi kepada kiai dan santri melalui wawancara dan observasi untuk memastikan temuan tersebut terjadi di pesantren yang diteliti. Perbedaan demografi pesantren menunjukkan disparitas dampak yang dirasakan. Pada pesantren mahasiswa seperti PP Inayatullah Sleman dan PPMH AlAzhar Banjar dominan merasakan manfaat TIK pada aspek pendidikan untuk mengakses berbagai informasi. Beragam konten yang tersedia mendorong motivasi belajar santri dikarenakan dapat mendukung pelajaran di pesantren dengan representasi yang menarik dan mudah dipahami. Misalkan bagi santri Wustho' (menengah) mencari bagan skematik i'rab (fasal yang membahas sintaksis bahasa Arab) agar mudah dihafalkan daripada memahami tekstual kitab pegon. Sedangkan bagi santri 'Ulya (atas) mencari kreasi nadzom Alfiyah Ibnu Malik (kitab yang membahas i'rab) dalam bentuk audio/video agar meningkatkan minat dan variasi dalam me-nadzom-kan.

Berbeda dengan pesantren murni tanpa pendidikan formal seperti PP API Magelang dan PP Hidayatul Mubtadien Lirboyo dominan merasakan manfaat TIK pada aspek dakwah untuk mempublikasikan artikel ataupun video pengajian sehingga memperluas sasaran dakwah. Masyarakat di luar pesantren dapat turut memperdalam spiritual dan menata moral. Terdapat aktifitas menarik dan menunjukkan diterimanya teknologi di pesantren yaitu saat mengaji bandongan santri merekam kegiatan tersebut yang langsung (live) dipublikasikan melalui akun media sosial pesantren ataupun kiai yang bersangkutan. Banyak channel Youtube milik pesantren dan kiai dengan sajian konten pengajian maupun kegiatan di pesantren, seperti Gus Yusuf Channel (akun pengasuh PP API Magelang), GusMus Channel (akun pengasuh PP Raudlatut Thalibin Rembang), Pondok Pesantren Lirboyo (akun resmi PP Hidayatul Mubtadien Lirboyo).

Selain aspek dakwah dan pendidikan, manfaat TIK pada aspek sosial bagi kedua demografi pesantren sama-sama memberikan pengaruh positif misalkan untuk humasi kepada alumni dan wali santri. Humasi dilakukan dengan mempublikasikan berita-berita terkait kondisi dan kegiatan di pesantren sehingga alumni dan wali santri mengetahui perkembangan yang terjadi. Salah satu manfaat nyata yang dirasakan pesantren dengan rutin melakukan humasi adalah di PP Inayatullah Sleman ketika merenovasi gedung banyak dukungan materil dari alumni dan wali santri untuk menunjang operasional. Pesantren yang hanya memiliki anggaran terbatas dapat menyelesaikan renovasi yang dilaporkan menghabiskan banyak biaya. Hal tersebut menunjukkan TIK memiliki kekuatan dalam menciptakan empati sosial.

Di samping manfaat yang telah dirasakan, TIK juga membawa efek buruk bagi pesantren. Pada aspek dakwah, kebanjiran informasi yang besar membuat kiai dan santri perlu selektif menerima informasi. Media sosial telah dipenuhi ustadz dengan cara dakwah yang berbeda-beda. Ceramah yang

Medika Teknika : Jurnal Teknik Elektromedik Indonesia, Vol 01 No. 1, Oktober 2019| 27 


\section{In'amurrohman}

Kesyubhatan TIK

disampaikan ada yang bernada rahmatan lil 'alamin, ada pula yang provokatif. Tidak sedikit santri yang mudah terprovokasi dikarenakan kurangnya wawasan. Santri diharapkan melakukan validasi ke berbagai sumber yang kredibel agar tidak terpengaruh dengan stereotip yang beredar.

Pada aspek pendidikan, kemudahan memperoleh informasi menimbulkan ketergantungan. Kemudahan tersebut justru menurunkan kreatifitas santri mengelola informasi dan menemukan pemahaman sendiri. Dahulu, santri banyak mengkaji kitab, namun saat ini semakin sedikit yang dikaji. Tersedianya kitab digital seperti Maktabah Syamilah penggunaannya pun masih rendah. Dengan banyak mengkaji kitab, apabila suatu ketika menemui permasalahan, santri dapat langsung menemukan solusinya tanpa perlu membuka. Selain itu, santri biasa melakukan bahtsul masail yang dibimbing ustadz ketika ada masalah. Akan tetapi, saat ini santri cenderung memilih cara instan dengan mencari jawaban di internet. Fenomena tersebut menunjukkan ketergantungan informasi mengakibatkan turunnya kreatifitas, minat belajar di pesantren, dan kemampuan berfikir santri.

Dampak negatif pada aspek sosial termasuk dampak yang paling dominan. Pesantren yang membebaskan penggunaan media elektronik mengakibatkan kecanduan. Santri ketika sudah asyik dengan gawai cenderung tidak memperdulikan rekan-rekan di sekitarnya maupun kegiatan di pesantren. Semisal ketika ro'an (kerja bakti), meskipun pengurus sudah memberikan instruksi namun terdapat perbedaan kepatuhan pada santri yang tidak menggunakan gawai dengan yang menggunakan. Bagi yang tidak menggunakan akan langsung mengindahkan dan mengikuti ro'an, sebaliknya santri yang asyik dengan gawai cenderung menunda-nunda bahkan tidak mengikutinya. Biasanya fenomena seperti itu dikarenakan santri sedang bermain game, menonton Youtube, ataupun mengakses media sosial.

\subsection{Kemampuan Literasi Media}

Penentuan tingkat kemampuan literasi media didasarkan pada kategori yang telah ditetapkan ICF meliputi dasar dengan rentang nilai kurang dari 70, menengah dengan rentang nilai antara 70 sampai 130, dan mahir dengan rentang nilai lebih dari 130 [15]. Pada penelitian ini, tingkat kemampuan literasi media dibedakan berdasarkan dimensi kemampuan teknis (KT), pemahaman kritis (PK), dan kemampuan komunikatif (KK) agar memberikan gambaran yang lebih rinci. Tabel 1 menunjukkan pemetaan kategori kemampuan literasi media untuk $u s t a d z$, pengurus, dan santri berdasarkan hasil perhitungan bobot indikator.

Tabel 1 Kemampuan Literasi Media

\begin{tabular}{|c|c|c|c|}
\hline Status & KT & PK & KK \\
\hline \multirow{2}{*}{ Ustadz } & 105.38 & 96.99 & 100.78 \\
\cline { 2 - 4 } & Menengah & Menengah & Menengah \\
\hline \multirow{2}{*}{ Pengurus } & 101.31 & 98.92 & 105.26 \\
\cline { 2 - 4 } & Menengah & Menengah & Menengah \\
\hline \multirow{2}{*}{ Santri } & 93.31 & 104.09 & 93.96 \\
\cline { 2 - 4 } & Menengah & Menengah & Menengah \\
\hline
\end{tabular}

Diperoleh bahwa kemampuan literasi $u s t a d z$, pengurus, dan santri pada ketiga dimensi semuanya berada pada tingkat menengah. Pada aspek penggunaan teknologi, ustadz memiliki kompetensi lebih tinggi daripada pengurus dan santri. Untuk pemahaman kritis justru santri yang lebih menguasai pengetahuan tentang konten dan regulasi media. Sedangkan pengurus lebih berkompeten dalam menjalin hubungan sosial dan pembuatan konten. 


\section{KESIMPULAN}

Berdasarkan hasil pengolahan data penelitian diperoleh simpulan:

Penggunaan TIK telah memberikan dampak positif bagi pesantren. Ketersediaan berbagai informasi memudahkan dalam pembelajaran. Setiap informasi yang dibutuhkan dapat ditemukan serta dengan sajian konten yang bervariasi sehingga santri berkesempatan memperluas wawasan.

Kecanduan penggunaan TIK dominan membawa efek buruk bagi pribadi dan sosial santri. Santri menjadi individualis dan hilangnya kepedulian pada pesantren. Santri sebagai sosok yang tawadhu' dan ta'dzim sedikit mulai luntur akibat terlalu jauh bermain di dunia maya dan melupakan dunia di dalam pesantren.

Tingkat kompetensi literasi digital seluruh santri baik dari kalangan ustadz, pengurus, maupun santri dari 32 pesantren berada pada kategori menengah. Hasil tersebut menunjukkan santri sudah cukup kompeten dalam penggunaan dan memahami regulasi media digital.

\section{DAFTAR PUSTAKA}

[1] S. N. Azizah, "Pengelolaan Unit Usaha Pesantren Berbasis Ekoproteksi," EKBISI J. Ekon. dan Bisnis Islam, vol. IX, no. 1, pp. 103-115, 2014.

[2] A. M. Fahham, "Standardisasi Kurikulum Pesantren," Maj. Info Singk. Kesejaht. Sos., vol. 9, no. 5, p. 2017, 2017.

[3] M. S. Zuhriy, "Budaya Pesantren Dan Pendidikan Karakter Pada Pondok Pesantren Salaf," Walisongo J. Penelit. Sos. Keagamaan, vol. 19, no. 2, p. 287, 2011.

[4] D. Susanto, "Pesantren dan Dakwah Pemberdayaan Masyarakat Islam," An-Nida J. Komun. Islam, vol. 6, no. 2, pp. 128-136, 2014.

[5] L. Harahap, "Rekonstruksi Paradigma Pendidikan Agama Islam Era Globalisasi," Al-Muaddib J. Ilmu-Ilmu Sos. Keislam., vol. 1, no. 1, 2017.

[6] M. I. Fitriani, "Kontestasi Konsepsi Religius dan Ritualitas Islam Pribumi Versus Islam Salafi di Sasak Lombok," Teosof. J. Tasawuf Dan Pemikir. Islam, vol. 5, no. 2, pp. 513-531, 2015.

[7] A. Rohman, "Hukum Toleransi Kelompok Salafi Terhadap Kelompok Islam Lainnya Di Kabupaten Banyumas," vol. 02, no. 1, pp. 377-388, 2003.

[8] A. Husaini, Islam Versus Kebebasan/Liberalisme. 2010.

[9] F. N. Stiftung, Islam dan Liberalisme. 2011.

[10] K. Ummatin, "Globalisasi Komunikasi dan Tuntutan Dakwah Bermedia," J. Dakwah, vol. 9, no. 2,2008 .

[11] S. Mohammadyari and H. Singh, "Understanding the effect of e-learning on individual performance: The role of digital literacy," Comput. Educ., vol. 82, pp. 11-25, 2015.

[12] V. Rambousek, J. Štípek, and P. Vaňková, "Contents of Digital Literacy from the Perspective of Teachers and Pupils," Procedia - Soc. Behav. Sci., vol. 217, pp. 354-362, 2016.

[13] W. Techataweewan and U. Prasertsin, "Development of digital literacy indicators for Thai undergraduate students using mixed method research," Kasetsart J. Soc. Sci., vol. 30, pp. 1-7, 2017.

[14] Kementerian Agama RI, "Statistik Data Pendidikan Diniyah dan Pondok Pesantren.” 2015.

[15] European Commission, "Testing and Refining Criteria to Assess Media Literacy Levels in Europe Final Report,” no. April. pp. 1-217, 2011. 